epidermal hairs, leaf anatomy, type of starch grains and basic chromosome numbers has led, in some instances, to a change in tribal position. Exhibits relating to the many Floras now being prepared at Kew were also on view in the Herbarium, while in the Library an interesting selection of botanical books and periodicals were laid out on the tables.

Many of the exhibits displayed by the curator and his assistants were primarily of horticultural interest although not lacking in scientific appeal to the student of botany. For example, the exhibit of a large number of species of Saxifraga illustrating the astonishing diversity in habit, form and geographical distribution could scarcely have failed to impress the teacher as well as the student.

Another garden exhibit, illustrating methods of climbing in plants, showed a series of living examples, other than text-book subjects, although some of the more popular species were also displayed. Semele androgyna, for example, is known to most students as an example of cladode development, although few would have guessed it was a climbing plant capable of attaining a height of $35 \mathrm{ft}$. The exhibit staged by the Arboretum Department concerning seed storage was devoted to the problem of maintaining viability of certain seeds of deciduous trees and shrubs. Under natural conditions the seed is shed into a moist leafy medium, where it normally remains until germination. With seeds which are collected and stored, the requisite conditions of moisture and aeration can be simulated by placing the collected seeds-acorns, for example-in polythene bags together with damp peat and maintaining them at a temperature of $36^{\circ} \mathrm{F}$. Viability can then be assured for several months. The problems involved in the germination of hard-coated seeds were also dealt with. The seeds of holly, Pyracantha and others with stony endocarps are subjected to 'stratification'. The seeds when gathered are placed in boxes of damp sand in successive layers and placed in the open. Here they are exposed to the elements for maybe a year or more, after which time the endocarps have become sufficiently softened to permit germination. Another method of accelerating germination depended on the principle of vernalization. A sample of Malus seed had been maintained at a temperature of $36^{\circ} \mathrm{F}$. for sixty days and then subjected to two I-sec. dips at 10 -min. intervals in water at $165^{\circ} \mathrm{F}$. The seeds then showed radicle development at an advanced stage and a batch of seed so treated had actually germinated within a few days.

An impressive exhibit displaying methods of vegetative propagation demonstrated the use of various growth-promoting substances in the quick establishment of cuttings. The formation of callus in treated and untreated examples was illustrated, and the methods used in propagation by leaf, root and stem cuttings were also demonstrated. A working mist-unit which automatically maintains a constant humidity in a propagating house was elso on view.

The exhibit in the Ferneries was notable for a fine display of young sporophytes of the rare monotypic Regnellidium diphyllum, a member of the Marsilia. ceae; few students could ever have seen living specimens of this interesting South American genus. In addition, there were examples of the early stages in the development of the fern sporophyte and an interesting demonstration of the vegetative propagation of species of Selaginella and Lycopodium. These genera, which are difficult or impracticable to raise from spores, are in most cases readily raised from leaf or stem cuttings.

In the Jodrell Laboratory a number of exhibits were displayed to illustrate the multifarious activities of its staff. Besides demonstrations of the methods used in preparing materials for microscopical examination, several examples were shown of commercial vegetable products which had either been adulterated with worthless material or were completely spurious.

Finally, mention should be made of the exhibit shown in the Herbarium, prepared and loaned by the British Council, consisting of forty-four panels illustrating the history and activities of the Royal Botanic Gardens, Kow. Intended primarily for displaying overseas, they were quite excellent in presentation and were universally admired.

F. BaLlard

\title{
INFLUENCE OF EDITORS
}

$\mathrm{T}$ HE question of how far an editor should go in correcting an author's manuscript was discussed on April 29 at a meeting of the Scientific Publications Council. Dr. G. E. W. Wolstenholme (Ciba Foundation) was in the chair.

Dr. R. D. Keynes (Cambridge) said an editor has a dual responsibility $(a)$ to the author and $(b)$ to the reader. Many authors submit manuscripts containing a long historical introduction and a discussion that is a wearisome repetition of the results. Sometimes the statistical evidence is inadequate, means are calculated incorrectly and the author gives figures that do not support what he says. However, conformity to a standard form of presentation should not be insisted on too rigidly, and in matters of taste the author should always have the last word. But an editor should insist on clarity; and he must be fierce in ensuring the accuracy of any data that are published. Some editors send the author a report from an anonymous referee, but anonymity is apt to cause resentment; an editor writing personally can often be much ruder and more effective without causing ill-feeling. As a university teacher, Dr. Keynes was concerned at the number of text-books and symposium volumes that bear the names of eminent scientists as editors, but in which the socalled editors have not really done any editing at all. The frequent contradictions in the different chapters are troublesome to student and teacher alike. Editorial interference may be objectionable, but editorial neglect is worse.

Dr. A. S. Parkes (National Institute for Medical Research) agreed that an editor had many responsibilities; but in the long run the author bears the full responsibility for every paper bearing his name. In particular, an editor should not rely too much on a referee, who may well have his own axe to grind, and who, being anonymous, has no right to try to insist on major alterations to someone else's paper. He recognized fully, from his own experience, that young authors can benefit enormously from the constructive criticism of more experienced writers; but 
papers should go through the moulding stage before they are sent for publication. The head of a department should see that all papers leaving it are in good shape and worthy to bear its name.

Prof. E. J. King (British Postgraduate Medical School) said that manuscripts written by scientists are often very poor, and heads of department cannot be expected to replace the experienced editor in the highly skilled task of revising for publication. Editing is a burdensome job, and most scientists are grateful to the editors who give their time to it. Editors should do as much rewriting as they think necessary. But an editor needs to be a diplomat: he must know how to effect a useful compromise without causing resentment.

Mr. A. L. Bacharach ( $J$. Nutrition) said that the basic question is: How much should an editor do? Some scientists are glad to have their manuscripts revised, but others go so far as to assert that papers should appear just as they are written, even complete with grammatical errors. The purpose of publication is to spread new information, and a paper will do this only if the reader has confidence in the author. Grammatical errors, verbosity and repetition undermine the confidence of the reader and should be corrected. It is helpful if manuscripts go through a process of 'internal editing' within a department (not necessarily by the head) before they are sent for publication. In one department that had adopted this procedure for more than fifteen years, only one in some two hundred of the papers sent for publication had been rejected or returned for rewriting. An editor is entitled to make every alteration he thinks necessary to improve the clarity and intelligibility of a paper, so that it can be read with intellectual comfort. Those who resist such alterations are generally the bad scientiststhe good ones are glad to have their papers improved.

Dr. R. K. Callow (National Institute for Medical Research) said that a part of the problem is that some scientists are completely blind to typographical, grammatical and logical errors and unable to understand the concern that others feel about them. In his experience, a journal in which an editorial board of scientists did most of the editing, and a staff editor did only sub-editing, achieved the happiest authoreditor relationship. It was less satisfactory to have a system of refereeing in which the expression of opinion was limited ('suitable' or 'not suitable' for acceptance) and papers were altered by a staff editor to fit them into a stereotyped scheme for the concise recording of data.

Dr. I. Bush (Oxford) complained of over-zealous editors and laggard referees who hold up publications while making numerous changes, which are not of the first importance, in the manuscripts. Editorial requirements are so numerous and various these days that many otherwise conscientious authors do not take the maximum trouble in preparing their manuscripts since experience leads them to believe that, whatever they do, the editors will always raise a large number of objections or alternatives. $\mathrm{He}$ pointed out that Dr. Detlev Bronk had recommended a decrease in 'editorializing' in an article some years ago.

Dr. T. H. Osgood (U.S. Embassy) said that in his American experience, the insensitivity of some authors to shades of meaning lent credibility to the story told by a fellow editor that occasionally his letters of rejection took the form: "Dear Sir, Although your paper fills a much-needed gap in the literature, I regret that it cannot be accepted for publication". It was unfortunate that editors were, on occasion, forced to undertake the education of authors, but when it became known that the correction of errors and the questioning of editorial judgment involved considerable delay, authors took exceptional pains to present good manuscripts. In view of the normal anxiety of an author to see his paper in print, the threat of delay was the best weapon for ensuring the effectiveness of editorial influence. An editor who did his job well must expect to make one or two enemies every year.

Mr. F. Clark (Biochemical J.) described the work of a professional editor, whose services may be required for large scientific journals where much of the editorial work formerly done by the chairman and other members of the editorial board can be transferred to the editorial office.

Dr. G. E. W. Wolstenholme (Ciba Foundation) said it is difficult for scientists from abroad to understand the requirements of journals in another country. Some scientists whose papers are rejected are convinced that the editors have a personal grudge against them.

This short meeting had shown how helpful it could be for authors and editors to get to know each other : in that way many mutual difficulties could be ironed out.
D. Richter

\section{THE BRITISH RAYON RESEARCH ASSOCIATION}

\begin{abstract}
$\mathrm{T}$ HE annual open days of the British Rayon Research Association's Heald Green Laboratories at Wythenshawe were held during May 11-13. The total attendance was 900 . Last year the work on 'fluid beds' and on vibration problems on spinning machinery was not demonstrated, but, because of the progress made, it was possible to give impressive demonstrations of both these aspects this year.

In the 'fluid beds', on which the Association has been working for the past few years, the bed material is small glass beads (dimensions $1 \mathrm{~mm} .-0 \cdot 25$ $\mathrm{mm}$.) and the fluidizing agent is air. The particular
\end{abstract}

virtues of fluid beds are : (a) that high rates of heat transfer can be achieved between a heat source in the bed and the material to be heated, for example, fabric or cord; (b) that the bed can be operated at high temperatures; and $(c)$ that the temperature is uniform across the bed. Fabric or cord can either be introduced at the bottom and removed from the top of the bed (single-pass bed) or both entry and removal can be at the top (double-pass bed), in which case it is passed round an internal roller or similar device at the bottom. The problem is to achieve this with low cloth tensions. The current position is that fabrics can be passed through single-pass beds under a tension 